\title{
PENGEMBANGAN MEDIA PEMBELAJARAN INTERAKTIF BERBASIS WEBSITE APPSGEYSERS TEMA LINGKUNGAN SAHABAT KITA KELAS V SD MUHAMMADIYAH 2 FULL DAY EDUCATION SANGATTA UTARA
}

\author{
Agus Sultonik, Muhammad Siddik, Sudarman \\ Universitas Mulawarman \\ agussultonik8@gmail.com
}

\begin{abstract}
This research aims to determine the effectiveness and feasibility of using Appsgeysers Media website against the enhancement of student learning motivation. This research was done in SD Muhammadiyah 2 Full Day education North Sangatta because the teaching and learning activities conducted in the school especially in thematic lessons have used multimethods and multimedia, only still limited to the use of Microsoft Power point Medi so still impressed less effective. This type of research uses research and development methods or commonly called research and development. Samples use Lee and Owens development design methods. While the samples are taken in the class $V$ (five) students, by using the pattern of one group Pretes and postest design. The Data used is a daily replay value before and after treatment, and then analyzed using test $t$. The results showed that interactive learning media based on website Appsgeysers used has a high level of effectiveness and feasibility. The high interest and motivation to learn that is high in the students 'interest also in teaching and learning activities. These findings are supported by the fact of the field where the average daily replay value of students increased $13.59 \%$ from 69.96 to 82.90 .
\end{abstract}

Keywords: Multimedia Website appsgeysers, thematic learning

\section{Pendahuluan}

Perkembangan ilmu pengetahuan dan teknologi telah membawa perubahan yang sangat signifikan terhadap berbagai dimensi kehidupan manusia, baik dalam ekonomi, sosial, budaya maupun pendidikan. oleh karena itu agar pendidikan tidak tertinggal dari perkembangan Iptek tersebut perlu adanya penyesuaianpenyesuaian ${ }^{1}$.Selain itu perkembangan ilmu pengetahuan dan teknologi semakin mendorong upaya-upaya pembaharuan dalam pemanfaatan hasil-hasil teknologi dalam proses belajar. ${ }^{2}$ Jenis kegiatan yang telah dilakukan adalah guru membuat sebuah aplikasi berbasis android yang diimplementasikan pada siswa siswa khususnya di SD Muhammadiyah 2 sangatta utara pada pelajaran Tematik dan dapat di gunakan untuk mata pelajaran yang lainnya seperti TIK, Bahasa Indonesia dan muatan pelajaran lainnya. Pada hakikatnya proses belajar mengajar merupakan sebuah proses komunikasi. Ada 3 komponen

${ }^{1}$ Asnawir dan Basyiruddin Usman, Media Pembelajaran, (Jakarta: Ciputat Pers, 2002), hlm 1

${ }^{2}$ Azhar Arsyad, Media Pembelajaran, (Jakarta: PT. Raja Grafindo

Persada, 1997), hlm 2 penting dalam proses komunikasi yang memainkan perannya yaitu: kurikulum tentang pesan yang disampaikan dalam proses belajar mengajar, komunikator dalam hal ini adalah guru dan komunikan dalam hal ini adalah siswa. Agar proses komunikasi berjalan dengan lancar atau berlangsung secara efektif dan efisien, diperlukan alat bantu yang disebut dengan media pembelajaran. ${ }^{3}$ Media audio-visual mempunyai fungsi dan peran sebagai berikut: ${ }^{4}$

a) Menembus ruang dan waktu. Dengan menggunakan media seperti film, foto ataupun gambar, siswa dapat mengetahui peradaban masyarakat di suatu tempat yang belum pernah mereka kunjungi.

b) Menerjemahkan pesan menjadi sesuatu yang esensial. Dengan melihat diagram atau tabel misalnya, siswa dapat memahami konsep dan prinsip-prinsip teori sulit yang telah dituliskan dengan berlembar- lembar halaman.

\footnotetext{
3 Munir. (2001). “Aplikasi Teknologi Multimedia Dalam Proses Belajar

Mengajar" Bandung: Jurnal Mimbar Pendidikan., 3 (20). 9 - 17.

4 Arsyad, Azhar. 2003. Media Pembelajaran. Jakarta: Raja Grafindo

Persada
} 
c) Memberikan pengalaman sosial dan emosiaonal

d) Memberi motivasi.

e) Memperjelas pemahaman.

Berangkat dari teori belajar, Rahardjo menguraikan hakekat belajar adalah interaksi antara peserta didik yang belajar dengan sumbersumber belajar di sekitarnya yang memungkinkan terjadinya perubahan prilaku belajar. ${ }^{5}$ Berbicara tentang interaksi dalam ranah proses belajar mengajar, media pembelajaran memiliki kemampuan-kemampuan yang berperan penting sehingga dapat meningkatkan motivasi, pemahaman serta prestasi. Yaitu:

1. Sebagai penarik perhatian, yakni sebagai penarik perhatian siswa, media bersifat mengundang perhatian peserta didik, meningkatkan rasa keingintahuan siswa, serta menyampaikan informasi.

2. Pelancar komunikasi. Yakni media dapat mendorong dan membantu siswa untuk memahami pesan tertentu yang ingin disampaikan oleh guru.

3. Retensi. Yaitu media membantu pembelajaran untuk mengingat konsep-konsep penting yang diperoleh selama pelajaran.

Secara etimologis multimedia berasal dari bahasa latin, yaitu dari kata "multi" yang berarti banyak; bermacam-macam dan "medium" yang berarti sesuatu yang diapakai untuk menyampaikan atau membawa sesuatu. Appsgeyser merupakan website yang dapat digunakan untuk membuat suatu aplikasi dan program pembelajaran secara professional dengan cepat. ${ }^{6}$ Membuat produk multimedia, softwere windows interaktif,. Hanya dengan drag and drop media files favorite, masukan foto, text, audio, video dan lainnya

\section{Metode Penelitian}

Dalam penelitian ini metode yang digunakan adalah metode penelitian dan pengembangan atau lebih dikenal dengan sebutan Research and Development. Metode penelitian Research and development ini adalah metode penelitian yang digunakan untuk menghasilkan sebuah produk tertentu dan menguji keefektifan produk tersebut ${ }^{7}$. Untuk dapat menghasilkan peroduk tertentu digunakan penelitian yang bersifat analisis kebutuhan dan untuk menguji keefektifan produk tersebut supaya dapat berfungsi di masyarakat luas, maka diperlukan penelitian agar dapat menguji keefektifanya, jadi penelitian dan pengembangan ini bersifat longitudinal atau bertahap.

Prosedur penelitian dan pengembangan dalam model Lee \& Owens terdiri dari lima tahap, yaitu (1) penilaian/analisis (assessment/analysis) yang meliputi analisis kebutuhan (need assessment) dan analisis awal akhir (front-end analysis), (2) desain (design), (3) pengembangan (development), (4) implementasi (implementation), dan (5) evaluasi (evaluation). Untuk lebih jelasnya langkah-langkah tersebut digambarkan dalam Gambar menurut Lee dan Owens ${ }^{8}$ dapat dilihat pada Gambar 1

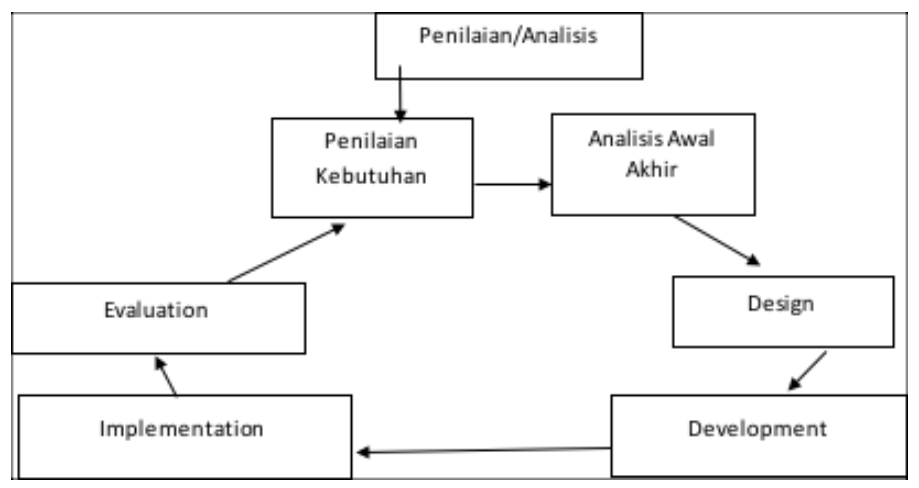

Gambar 1 Langkah pengembangan Lee dan Owens ${ }^{3}$

\footnotetext{
5 Raharjo. (2006). Media pendidikan Pengertian, Pengembangan dan Pemanfaatanya. Jakarta: Pustekom dan Raja Grafindo Persada

${ }^{6}$ Raharjo. (2006). Media pendidikan Pengertian, Pengembangan dan

Pemanfaatanya. Jakarta: Pustekom dan Raja Grafindo Persada
}

\footnotetext{
${ }^{7}$ Sugiyono .Metode penelitian Kuantitatif, Kualitatif dan R\&D.(Bandung :Alfabeta,2011),Hlm 297

${ }^{8}$ Lee, W. \& Owens, D, L. 2004. Multimedia Based Instructional Design, Second Edition. United States of America: John Wiley \& Sonc, Inc.
} 
Penelitian dan pengembangan Lee dan Owens ${ }^{9}$ menyatakan "Research and Development $(R \& D)$ is a process used to develop and validate educational products." Sedangkan menurut sumber lain, metode penelitian dan pengembangan adalah metode penelitian yang digunakan untuk menghasilkan produk tertentu, dan menguji keefektifan produk $^{10}$. Namun karena keterbatasan waktu dan biaya, maka model Lee dan Owens tersebut dimodifikasi untuk disesuaikan dengan pengembangan yang akan dilakukan.

\section{Prosedur Pengembangan Pembelajaran}

Alasan dipilihnya model ini dikarenakan beberapa hal antara lain adalah : (1) Model ini sudah dikenal luas dan sudah terbukti memberikan hasil yang baik. (2). Model ini merupakan suatu model yang procedural yaitu model yang bersifat deskriptif. (3). Tahap pengembangan dalam model ini sama dengan standar tahap research and development.

Berdasarkan pada model pendekatan system desain pembelajaran lee \&owen sebagaimana disebutkan diatas, maka prosedur pengembanga dalam penelitian pengembangan ini mengikuti langkah langkah yang diinstruksikan dalam model desain sebagaimana berikut ${ }^{11}$ :

\subsection{Analisis}

Pada tahap analisis ini terdiri dari beberapa kegiatan yang akan dilakukan,

1. Analisis kebutuhan dan karakteristik siswa

2. Analisis materi pembelajaran

3. Analisis literatur

\subsection{Desain}

Pembuatan sebuah produk biasanya dimulai dari menganalisa suatu produk serta pengumpulan bahan pembuatan produk tersebut seperti referensi, pemilihan software yang tepat dan Analisa kekurangan serta kelebihan dari produk yang akan dikembangkan yang membutuhkan waktu dalam produk ini kurang lebih 3 bulan

\subsection{Development (Pengembangan)}

Pengembangan adalah proses mewujudkan desain produk menjadi kenyataan ${ }^{12}$ Dalam

\footnotetext{
${ }^{9}$ Lee, W. \& Owens, D, L. 2004. Multimedia Based Instructional Design,

Second Edition. United States of America: John Wiley \& Sonc, Inc.

${ }^{10}$ Sugiyono. 2010, Metode penelitian Pendidikan pendekatan kuantitatif,kualitatid, dan R\&D. Bandung :Alfabeta
}

penelitian ini, produk yang dikembangkan Aplikasi pembelajaran web appsgeysers. sehingga pada tahapan ini yang dilakukan adalah desain/view Aplikasi yang telah ada dikembangkan sesuai dengan tujuan pembelajaran. Pengembangan desain dilanjutkan dengan evaluasi formatif.

\subsection{Implementasi}

Implementasi adalah langkah nyata untuk menerapkan produk pembelajaran yang sedang dibuat. Pada tahap ini semua yang telah dikembangkan diset sedemikian rupa sesuai dengan fungsinya agar bisa diimplementasikan ${ }^{13}$.

\subsection{Evaluasi (evaluasi formatif)}

Setelah media pembelajaran diaplikasikan kepada siswa, selanjutnya dilakukan evaluasi formatif .

2. Tahap pengembangan media pembelajaran

1. Tahap analisis situasi awal

2. Tahap pengembangan rancangan Media appsgeysers

3. Tahap pembuatan Media aplikasi di appsgeysers

4. Tahap penilaian Aplikasi media pembelajaran berbasis Apps geysers

3. Uji coba produk media pembelajaran

\subsection{Desain uji coba}

3.1 Tahap Konsultasi

4.1 Tahap validasi ahli

5.1 Tahap uji coba lapangan

\subsection{Subjek Uji coba produk}
a) Ahli isi
b) Ahli Materi
c) Ahli media
d) Siswa di kelas

5. Instrument Pengumpulan Data

Masing masing siswa mengisi angket untuk memberikan penilaian terhadap kualitas media tersebut.berupa Angket dianalisis menggunakan Hasil Pre test dan post test

A. Waktu dan tempat kegiatan

Waktu pembelajaran menggunakan media appsgeyser ini adalah bulan September 2019

\footnotetext{
11 A. Pribadi, Benny. (2009). Model Desain Sistem Pembelajaran. Jakarta: PT Dian Rakyat.
} 
Tempat kegiatan ini dilakukan di SD Muhammadiyah 2 sangatta Utara

\section{Hasil Penelitian Dan Pembahasan}

Berdasarkan hasil pengolahan dan analisis data terhadap data hasil pre test,post test dan angket yang telah dilakukan, mengenai pembelajaran multimedia interaktif berbasis Website appsgeysers ini diperoleh kesimpulan sebagai berikut :

a. Rata-rata hasil pre-test yang menunjukkan kemampuan awal siswa pada kelas V SD Muhammadiyah 2 full dya education pada mata pelajaran Tematik sebesar 69,96 \%. Setelah melalui kegiatan belajar mengajar dengan model pembelajaran interaktif berbasis multimedia Website appsgeysers ini, nilai rata-rata siswa meningkat menjadi 82.90 naik $18.49 \%$. Hal ini menunjukkan penggunaan media pembelajaran ini sangat efektif dan untuk meningkatkan hasil belajar secara maksimal

b. Dilihat dari indikator ketuntasan belajar, pembelajaran multimedia interaktif berbasis Website appsgeysers ini sangat berperan dalam meningkatkan minat, motivasi dan hasil belajar siswa terhadap suatu materi pelajaran secara tuntas yang lebih baik daripada pembelajaran konvensional

c. Siswa siswi lebih semangat ketika mengerjakan pekerjaan rumah menggunakan gadget,terbukti ketika PR diberikan secara konvensional (mengerjakan di buku) tidak semua siswa mengerjakan, akan tetapi dengan menggunakan multimedia berbasis android ini anak anak hamper semua mengerjakan tugas sebelum waktu yang di tentukan, artinya lebih cepat.

Beberapa masalah yang sering terjadi adalah mereka tidak diperbolehkan membawa handphone ke sekolah, karena orang tua takut hp nya rusak atau hal hal yang tidak diinginkan seperti hilang dan lain lain. Permasalahan itu bias di atasi dengan memberikan surat kepada orang tua dan sekolah memastikan bahwa semua handphone aman, karena ketika sampai ke sekolah handphone sudah dititipkan kepada guru wali kelas masing masing. Handphone hanya bias di pakai ketika pembelajaran, sehingga memperkecil resiko hilang atau rusak.

Masalah kadang juga muncul ketika beberapa anak tidak membawa handphone, sehingga dia tidak bisa mengikuti pembelajaran, solusi nya adalah hp bisa di gunakan secara bergantian, sehingga tidak ada alasan anak untuk tidak ikut belajar.

\section{Kesimpulan}

Dalam kegiatan belajar mengajar yang mengarah kepada aktivitas fisik, dimana secara teknis guru harus merencanakan keterlibatan siswa agar lebih aktif dan interaktif dalam proses belajar di kelas. Misalnya, dimulai dari menyiapkan segala kebutuhan belajar, memberikan kesempatan waktu kepada peserta didik untuk ikut berfikir dan bergerak aktif sampai pada pemberian motivasi belajar melalui media pembelajaran yang menarik. Penekanan pada aktivitas fisik semacam ini mengarahkan siswa agar lebih fokus dan semangat menerima materi yang disampaikan selama proses belajar berlangsung.

Pembelajaran Menggunakan handphone berbasis website appsgeysers ini sangat interaktif ,Sehingga dalam pemanfaatannya media ajar Menggunakan handphone berbasis website appsgeysers ini, guru berperan sebagai fasilitator, dimana guru menyampaikan materi pelajaran melalui media ajar tersebut kemudian siswa meresponnya dengan cara melihat, mendengar dan menjawab soal- soal yang ada di handphone masing masing.

\section{Daftar Pustaka}

Asnawir dan Basyiruddin Usman, Media

Pembelajaran, (Jakarta: Ciputat Pers, 2002), hlm 1 Azhar Arsyad, Media Pembelajaran, (Jakarta: PT.

Raja Grafindo Persada, 1997), hlm 2

Sudana Degeng, Ilmu Pengajaran Taksonomi

Variabel (Jakarta: Depdigbud 1989), hal 150

Smaldino, S. E., Lowther, L. D., Russell, D. J. 2008. Instructional Technology and Media for Learning. New Jersey: Pearson Merrill Prentice Hall.

Safaat H, N, Pemograman Aplikasi Mobile

Smartphone dan Tablet PC Berbasis

Android,Informatika: Bandung,2012.

Majid, Abdul. (2013). Strategi Pembelajaran. 
Bandung: PT Remaja Rosdakarya.

E. Mulyasa,(2013) Pengembangan dan

Implementasi Kurikulum 2013, (Bandung: PT

Remaja Rosdakarya), hlm 104-106

https://yossiekudotcom.wordpress.com/2011/09/27

/pembelajaran-berbasis-multimedia/ diakses

tanggal 1 Nopember 2020

Darmawan, D. (2016). Mobile Learning: Sebuah

Aplikasi Teknologi Pembelajaran. Jakarta:

RajaGrafindo Persada.

Dikkers. S., Martin. J., Coulter. B., et al. (2011).

Mobile Media Learning: Amazing Uses of Mobile

Devices for Learning. USA: ETC Press.

Munir. (2012). Pembelajaran Jarak Jauh Berbasis

Teknologi Informasi dan Komunikasi. Bandung:

Alfabeta

http://www.appsgeyser.com

Arnold, S. \& Garza. (2014). The Flipped

Classroom Teaching Model and Its Use for

Information Literacy Instruction. Communication in Information Literacy. 8, 7-22.

Mergler, A. G., \& Spooner-Lane, R. (2012). What Pre-service Teachers need to know to be Effective at Values-based Education. Australian Journal of Teacher Education, 37(8).
Amri, Sofan. Pengembangan dan model pembelajaran dalam kurikulum 2013, Jakarta: Prestasi Pustaka, 2013.

Arikunto, Suharsini. Prosedur Penelitian Suatu Pendekatan Praktek. Jakarta: Rineka Cipta: 2006.

Arie Sandy, Teguh. Modul Workshop \#22 Multimedia Interaktif, Makalah disampaikan pada Pelatihan Pembuatan AutoPlay, Flipbook Maker dan Quiz Creator. Aula Perpustakaan Universitas Negeri Malang.

Arsyad, Azhar. Media Pembelajaran, Jakarta: PT. Raja Grafindo Persada, 1997.

Carey, Lou and Walter Dick. The Systematic Design Of Instruction. USA. 1978. Dikutip dalam Proposal Tesis Husni Mubarok Pengembangan Media Ajar berbasis Autoplay. Dalam Pembelajaran PKN Kelas III di SDI As-Salam Malang.

Chatib. Munif. Sekolahnya Manusia, Bandung: Mizan Pustaka, 2009. Daryanto, Media Pembelajaran, Yogyakarta: Gava Media, 2010.

Lee, W. \& Owens, D, L. 2004. Multimedia Based Instructional Design, Second Edition. United States of America: John Wiley \& Sonc, Inc. 